\section{Public-private partnership in a smart city: A curious case in Japan}

International Review of Administrative

Sciences $1-16$

(C) The Author(s) 2021

Article reuse guidelines: sagepub.com/journals-permissions DOI: I0.1 I77/002085232II05।839

journals.sagepub.com/home/ras

@SAGE

\title{
Daniela Pianezzi
}

University of Essex, UK

\section{Yuji Mori}

University of Shizouka, Japan

\section{Shahzad Uddin}

University of Essex, UK

\begin{abstract}
Previous studies have overlooked how partnerships between public and private actors (PPPs) play out as an effect of cultural and historical conditions in the context of a smart city. Our analysis investigates the peculiar context of Japan, where smart city initiatives stem from a historically and culturally embedded "partnership" between government and businesses. Unlike other smart city settings, the adoption of a neoliberal logic of an all-embracing market world by prioritizing business interests over other civic issues is not inevitable. This paper contributes to the literature on PPPs and smart cities by presenting the case of a partnership between public and private actors that overcomes the antagonistic and transactional relationship problematized in previous studies. We demonstrate that the workings of PPPs are historically and culturally embedded. Thus, we caution policy-makers against adopting a universal framework for partnerships in smart city initiatives. In the case of Japan, we advocate for long term orientations of projects instead of the short-term goals espoused by smart city initiatives.
\end{abstract}

\section{Keywords}

public-private partnership, smart city, Japan

\section{Corresponding author:}

Daniela Pianezzi, University of Essex, Wivenhoe Park, Colchester CO4 3SQ, UK.

E-mail: daniela.pianezzi@essex.ac.uk 


\section{Introduction}

Smart cities have been defined in the literature according to three key criteria: smart technology, smart people and smart collaboration (Appio et al., 2019; Baron, 2012; Meijer and Bolívar, 2016). The urban deployment of smart technology (information and communication technologies) is key in the smart city discourse (Angelidou, 2017; Baron, 2012), but several studies have also suggested that it is the inhabitants that make a city "smart" (Meijer and Bolívar, 2016). In other words, smart cities are those that attract and cultivate highly educated people (Shapiro, 2006).

The third criterion, i.e. "smart collaboration", the focus of this study, refers to the involvement of a wide variety of stakeholders - including citizens - in the governance of the city (Ruhlandt, 2018). In particular, "smart collaboration" calls for local governments to partner with companies to address wicked urban problems, such as population health, pollution, and climate change (Koppenjan et al., 2004). Despite "smart collaboration" being seen as a distinctive characteristic of smart cities (Appio et al., 2019; Nesti, 2020; Rodríguez-Bolívar, 2015), we know little about how public and private actors collaborate to transform a city into a smart city (Rodríguez-Bolívar, 2015). The collaborative model of public-private partnerships (PPPs) has offered a blueprint for the development of smart city projects but there is little literature exploring its adoption in the smart city context (Liu et al., 2020; Ruhlandt, 2018). Our study addresses this gap by investigating how do public and private actors collaborate in transforming a city into a smart city?

In carrying out this investigation, we build on previous studies that have analyzed PPPs as a contingent and culturally situated practice (Koppenjan and de Jong, 2018; Steijn et al., 2011). As noticed by Wang et al. (2018), "informal institutions (e.g. culture and custom)" (p. 312) may influence the adoption and success of PPPs. These partnerships, which originated in the USA, indeed acquire different forms in contexts with different governance traditions (Koppenjan and de Jong, 2018; Steijn et al., 2011). The Japanese case is one that deserves in-depth investigation because of the highly distinctive historical patterns of partnerships between private and public actors (Hollands, 2015). In particular, values that are characteristic of the Japanese culture, such as "stability, goodwill and mutual obligation" (Domberger et al., 1997: 778), are said to enable cooperative rather than contractual relationship between organizations. This paper thus explores how PPPs have emerged in the Japanese context with a specific view on smart city initiatives.

The following sections offer an overview of the existing literature on PPPs in smart cities and a description of the research method adopted in the study. We then provide a critical discussion on PPPs in Japanese smart city initiatives with a focus on Yokohama City. The paper finishes with some concluding remarks.

\section{PPPs in smart cities}

Public-private partnerships are a key component of neoliberal reforms such as new public management, which praises private sector involvement in public decision-making and in the delivery of public services (Hood, 1991). Despite the global diffusion of 
neoliberalism, Bockman and Eyal (2002) argue that different forms, molded by local needs and through the epistemic inputs of local expertise, have emerged in varieties of countries. Neoliberal practices such as PPPs are no exception. Indeed, PPPs have been found to be geographically and historically specific (Brenner and Theodore, 2002; Steijn et al., 2011, 1236; Koppenjan and de Jong, 2018).

Originated and developed in the US and UK context (Domberger et al., 1997), the idea of "partnering" suggests that public and private actors can reconcile potentially conflicting values, beliefs, and practices by reaching an agreement via contracting and transactional arrangements (Koppenjan et al., 2004; Reeves, 2008; Reissner, 2019). These contractual arrangements typically see the private actor incurring the initial financing cost upon payment of a lease fee by the public actors over the life of the contract, such as the Private Finance Imitative in the UK in the 1990s (Broadbent et al., 2003; Koppenjan and de Jong, 2018). However, these initiatives showed several pitfalls, such as loss of political control, fragmentation of responsibilities, inaccurate risk calculation, and a clash of ethos between the public and private contractors (Broadbent et al., 2003).

Recent literature suggests that the transactional PPP approach may well be ill equipped to address the specific challenges characterizing collaboration in smart city projects (Liu et al., 2020). These require substantial investments in technological innovation, which makes risk-sharing arrangements between public and private actors even more complex (Liu et al., 2020). Furthermore, the development of long-term and collaborative partnerships is of greater importance in the smart city context owing to security issues linked to the gathering and use of citizens' data by companies (Veselitskaya et al., 2019). A shift from transactional to collaborative partnership is therefore of great importance for smart city development (Liu et al., 2020).

The few studies on this topic suggest that models of smart city PPPs are still in the making but there is a prevalence of top-down over bottom-up arrangements (with a stronger public or private roles, respectively; Rodríguez-Bolívar, 2015; Angelidou, 2017). Some argue that the infusion of the private sector into public projects has led to private corporations acquiring undue influence in defining and solving urban problems (Brenner and Theodore, 2002; Grossi and Pianezzi, 2017; Hollands, 2015; Lombardi and Vanolo, 2015; Vanolo, 2014). It is not uncommon to find local governments prioritizing private interests over public ones (Söderström et al., 2014; Vanolo, 2014). A case in point is New Songdo City in South Korea (Hollands, 2015: 8).

In contrast, other studies demonstrated the stronger role of the state in smart city partnerships (Angelidou, 2017; Appio et al., 2019; Datta, 2015). For instance, national and local governments in China and India have often exercised a strong top-down political and administrative leadership, in line with a more bureaucratic and centralized model of governance (Angelidou, 2017; Appio et al., 2019; Datta, 2015). Datta (2015) shows how governments have played an active role in the advent of the smart city utopia. These heterogeneous experiences warrant further exploration of how PPPs are established in smart city initiatives and the role that local context including economic, cultural and historical factors plays in this process. This will be the focus of our empirical analysis. 


\section{Methods}

Our explorative study draws on secondary and primary data. Secondary data included existing scholarly literature on Japanese history and culture, and documents and reports concerning Japanese smart city initiatives from government sources, international and national institutions, and business organizations. Among these initiatives, we focused on Yokohama smart city, the most advanced of the Japanese smart cities.

Primary data included interviews averaging an hour's duration with key members of the Yokohama Smart Business Association (YSBA). This association was formed in 2015, comprising Yokohama City and five private companies. The interviews involved 18 officials of Yokohama City and 13 corporate managers working on smart city projects in Yokohama. A three-part interview moderation guide was tailored to reflect the participating organizations' mandates. Interviews with officials of Yokohama City focused on the motives for and nature of participation in smart city projects and relationships with YSBA companies. Participating YSBA companies were interviewed to establish the nature of their participation and their reasons for participating in smart city projects, the benefits and challenges of relationships with the city, and relationships with other companies in the context of the YSBA. Each interview was recorded, transcribed, translated into English and content-analyzed using NVivo.

Our analysis consisted of three stages (Gioia et al., 2012; Nag and Gioia, 2012; Turner and Rindova, 2012). First, the transcripts were coded inductively by identifying concepts emerging in the interviewees' narrative. Second, we grouped and organized these concepts into second-order themes aiming at capturing similarities and differences among the concepts developed by different interviewees (See Figure 1). Third, we further reflected on these concepts by moving back and forth from the relevant literature and secondary documents to the second-order themes identified in the interviews. This "cycling" (Gioia et al., 2012, 21) was key in our theorization of the data. The discussion about the different interpretations of the second-order themes indeed led to a consensus around three main aggregate dimensions: "sponsored capitalism", "Japan incorporated", and the "samurai ethos". The latter will be discussed in Section 5 .

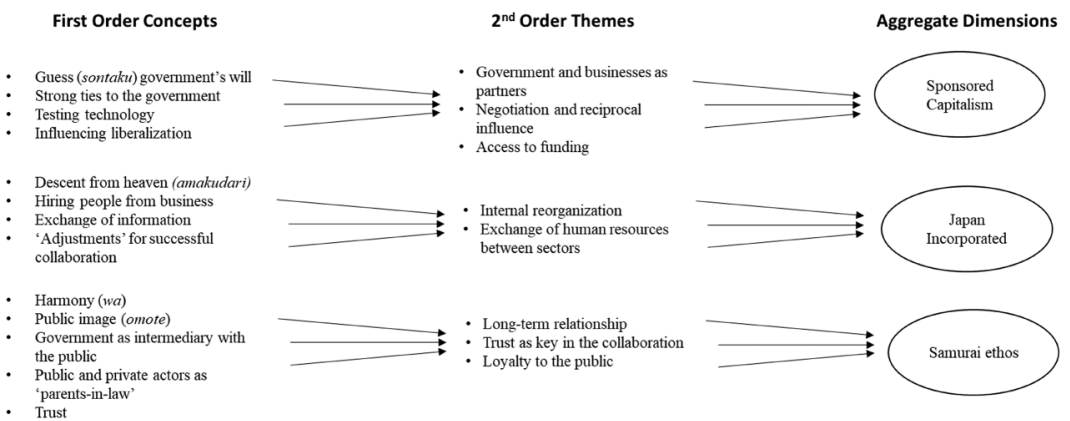

Figure I. Data structure inspired by Gioia et al. (20/2). 


\section{PPPs in Japanese smart cities}

The Japanese government started to promote the ideals of a smart city in the early 2000s. In particular, the Ministry of Economy Trade and Industry (METI) identified reductions in carbon dioxide emissions as a key strategic goal and called for collaboration between local governments and private companies to solve this crucial urban problem. In 2010, the government solicited funding for "next-generation energy and social system demonstration projects" in Japanese cities.

The national government-led energy projects were welcomed by Japanese cities. Only four out of 16 cities-Yokohama City, Kitakyushu City, Keihanna District and Toyota City-were selected by the government for funding. The overall budget for these pilot projects was 126.52 billion yen, with two-thirds coming from the national government and one-third from the private sector (Mah et al., 2013). The private corporations, endorsed by the local governments, formulated and submitted their own proposals directly to the national government (Mah et al., 2013). All projects were centered around energy efficiency, such as home energy, building energy and community energy management systems and electric vehicles.

Yokohama City received 74 billion yen, making it the largest recipient of these pilot projects. This is perhaps partly because Yokohoma city had already developed urban projects in collaboration with private companies that led to its designation as "Eco Model City" by the Japanese government in 2008, and "Eco 2 City" by the World Bank in 2009. Following the completion of these energy pilot projects in 2014, new smart city projects were launched under the "Future City programme" by the national government. The main difference was that these projects were carried out without the solid promise of national government funding (Mah et al., 2013; Pham, 2014). In spite of this, numerous smart city projects have been launched. In December 2019, the Smart City Public-Private Partnership Platform was established by the METI in collaboration with the Cabinet Office, the Ministry of Internal Affairs and Communications, and the Ministry of Land, Infrastructure, Transport and Tourism to promote these projects in a coordinated manner. This platform currently lists projects developed by 134 local governments including Yokohama City and 301 companies. However, the second-phase smart city projects rely almost entirely on funds from private corporations. At times, the projects are initiated by the latter, and at other times by the local governments. In some cases, smart city projects have seen a limited involvement of local governments, such as in the case of the Fujisawa Sustainable Smart Town set up by Panasonic and the Hitachi Smart Industrial Town led by Hitachi (Pham, 2014).

An example of smart city projects initially co-funded by the national government and private corporations but jointly run by private corporations and the local government is the Virtual Power Plant project in Yokohoma. In the first stage (2010-2014), an experiment was conducted to cut the peak voltage by discharging the electricity stored in a storage battery at the peak time. The experiment was then followed by a second stage with the storage battery being installed as a Virtual Power Plant at 18 elementary schools in 2016 but fully financed by private corporations such as TEPCO Energy Partner and Toshiba. 
In summary, from 2010 to the present in Yokohama and other Japanese smart cities, private participation in projects that serve public interests, such as carbon emissions reduction, has differed distinctly from that in traditional and Western PPPs. First, private corporations investing in these energy-saving projects have no expectation of recouping their investments from the government. Second, the Japanese smart city cases suggest more complex collaborative dynamics than can be found in contractual-oriented and transactional PPPs. Local governments' financial contributions to these projects are insignificant, as they play a largely coordinating role. Their main job is to encourage private corporations to propose projects aligned with national agendas on carbon emissions and climate change. Third, local governments use their public image to attract private companies to participate in smart city projects. It seems important for the companies to be associated with both the central and local governments. These differences make the nuances and complexity of smart city PPPs particularly interesting to explore. The next section draws on historical and cultural studies on Japan and evidence from the Yokohama case to explain why private actors in Japan are ready to collaborate in smart city projects.

\section{The Japanese model of smart city PPPs}

The above described characteristics of Japanese smart city PPPs, as we will demonstrate, are historically constituted and culturally derived. In particular, they are rooted in three key factors: "sponsored capitalism", "Japan incorporated", and the "samurai ethos".

\section{I Sponsored capitalism}

The government's call for private partners to participate in the national agenda, channeled by local governments, is rooted in the Japanese political and economic history. The Meji Restoration of 1868 was a key transition point in Japanese history (Bestor et al., 2011) when the government that had ruled Japan over the previous 250 years was replaced by a new government that aimed to promote industrial development while protecting traditional values. Its primary objective was to industrialize Japan, and it, therefore, played a crucial role in boosting strategic industries through financing. Key financial institutions remained under state control. Governmental control of banks and foreign exchange control laws, introduced in the 1930s, prevented Japan from becoming dependent on foreign capital.

Even when the banks were not under direct state control, relationships with the government facilitated access to loans from commercial banks and were therefore of primary importance for industries (Fulcher, 1988; Kaplan, 1972). To direct industrial development, a state agency now known as METI set industrial policy objectives on channeling resources into private corporations that were considered to be strategic and would achieve exceptional economic growth (Fulcher, 1988). In the 1970s, the central bank provided as much as $84 \%$ of private corporations' total financing.

This financing had reduced to 44\% by 1984 (Schwartz, 2001: 28). Furthermore, many of the restrictive regulatory frameworks were abolished or relaxed in 1980s in line with 
international neoliberal trends. A case in point was the electricity sector, whose key players are the main protagonists of smart city initiatives. In the 1990s, the government started to adopt new public management-oriented reforms to deregulate and liberalize the electricity sector. The objective was to increase competitiveness by reducing electricity rates (Kikkawa, 2021). At that time, 10 electric utilities supplied $88 \%$ of the electricity consumption in Japan (Jones and Kim, 2013).

However, since then the market liberalization has been "slow and ineffective" (Jones and Kim, 2013: 14) with the few general utility companies preserving their regional monopolies (Jones and Kim, 2013). As of March 2020, approximately 80\% of total electricity sales were still generated by the 10 existing major power companies (including Tokyo Electric Power Company-TEPCO; Kikkawa, 2021). Against this backdrop, many corporate managers in Yokohama's smart city projects reported that their companies see smart city PPPs as an opportunity to influence government policy-making. The liberalization of the electricity sector is indeed critical for many participants (Mah et al., 2013) and, in spite of neoliberal reforms, Japanese state agencies continue to substantially influence the country's economic life, owing to power derived from "longstanding business-government relationships, respect for the bureaucrats-and sanctions" (Schwartz, 2001: 27).

This influence is reflected in the role played by the METI as main promoter of the smart city agenda. One corporate participant in Yokohama City reflected on the government invitations to participate in the agenda: "Instead of saying 'cannot' you should say 'next year', or 'I'll think about it"'. Companies feel compelled to respond positively to governmental smart city initiatives. This emerged in our conversation with corporate managers. One corporate manager commented on the type of obligation that corporations feel toward the government's requests:

Since the government funding is open to the public, there is no clear request for participation, but it was stated that "I [the government] want you to come out." This is the world of "conjecture" in Japanese [...] it was asked by the government office to come over through a "survey of intentions". If your answer was "difficult", they say "I want you to reconsider". It means, "take part".

This quote suggests that, when evaluating the "worthiness" of smart city initiatives, the companies feel obliged to comply with the government's requests, guess (sontaku) its wishes, and behave accordingly. Local government can also take advantage of its ties with the national government. For instance, a city official explained that "The company is joining because of Yokohama's strong ties to the national government".

The Japanese government's traditional role in the country's economic life endows it with important leverage to direct industrial development toward areas deemed nationally strategic. For instance, following the Great East Japan Earthquake and the explosions at Tokyo Electric Power Company's Fukushima Power Plant in 2011, the METI decided to shut down all nuclear power generation in Japan and radically change its energy strategy, shifting from nuclear power (which represented one-third of the total energy production) to renewable energy, which at the time was less than $3 \%$ (Jones and Kim, 2013). In this 
respect, the promotion and development of the renewable energy sector through smart city initiatives appears to be a shared interest in business-government partnerships. This partnership privileges a focus on innovation, efficiency, and performance. By joining the initiative, participating companies can not only influence policy-making but also innovate and improve their smart-grid technologies: "The purpose of this pilot smart city project is to confirm whether or not it will be established as a business, so profitability is not a priority" (YSBA corporate participant). Another corporate manager commented:

We expect to participate in some projects that create a market there. Once the market is established, we will develop our business there, but we have to identify various factors before doing so. We may have to wait for the technology to mature and devise ways to make it profitable. [...] If various conditions are not arranged, it will not become a full business.

The sub-projects subsumed under the umbrella term "smart city project" all revolve around energy management and are experimental in character. Companies are invited to experiment with innovative technologies in the city while contributing to energy saving and consequently carbon dioxide emission reduction. The smart city is thus configured as a space where companies can test their technologies and establish a space for themselves in future and international markets.

Companies intend to test their smart technology in Japanese cities and then commercialize them abroad with the support of the METI. The latter indeed works closely with the Japan Bank for International Cooperation to increase Japanese companies' future global market share. The government thus aims at revitalizing economic growth by boosting businesses' technological innovation both locally and globally.

Corporate participation in smart city initiatives thus ensures continuity with domestic conventions that see government and businesses as partners in industrial development and global competition. This Japanese model of "sponsored capitalism" (Lockwood, 1965) represents a compromise between the top-down, central planning of socialist countries such as China and the capitalist model of the USA. The most interesting aspect of this model is that "neither government nor business necessarily imposes its will on the other or assumes leadership unilaterally" (Kaplan, 1972: 15). Starting from the Meiji Restoration, Japan's political framework has indeed been gradually remolded to incorporate the ideals of liberal democracy. As a result, the government's power has been partially offset by a rising civil society and corporate power. The latter, though, has always been inextricably linked to state power, as explained in the following section.

\subsection{Japan incorporated}

The term "Japan incorporated" has been coined to describe a "close-knit cooperation between government and business" (H. Nakamura, 1978: 68). The idea is that the Japanese government and businesses collaborate so closely that Japan as a whole can be seen as a single corporation, with the government functioning as the headquarters of numerous branches, i.e. Japanese industries. Other formulas such as "concerted 
economy" and "participatory partnership" are also used to describe this relationship (Kaplan, 1972). This is rooted in Japanese economic history.

Japan was historically characterized by the domination of a few powerful financial and industrial conglomerates, the "zaibatsu". The key members of these groups were former state officials (Fulcher, 1988). Even after their partial dissolution, these conglomerates re-emerged as keiretsu, and the boundaries between businessmen and bureaucrats remained blurred. For instance, businessmen still occupy the majority of seats on advisory councils (shingikai) set up by the ministries to enhance the policy-making process (Schwartz, 2001). The objective of these councils is to coordinate and settle competing interests, thus laying the ground (nemawashi) for policy implementation. Constant communications, exchanges of opinions and partnerships between bureaucrats and businessmen privilege "pragmatic social compromises" (Hirschmeier, 1970: 13).

Furthermore, over time it became common practice for bureaucrats who retired in their fifties to find employment in industry and banking, a practice called amakudari-literally, "descent from heaven" (Kaplan, 1972; Schwartz, 2001). This career path facilitated interactions between the government and industries seeking to direct the country's industrial development. This practice is still widely in use today and in the smart city context. For instance, according to a 2011 survey by the METI, 68 METI officials were re-employed as directors or advisors at the 10 regional power companies in the last 50 years. Many of them were hired as advisors and executives (The Nikkei, 2011). Along the same lines, between 2011 and 2015, 17 METI officials were re-employed in organizations set up by power companies (The Tokyo News Paper, 2015).

In line with these historical trends, Yokohama's transformation into a smart city was enabled by a set of management changes aimed at blurring the boundaries between businessmen and bureaucrats. To begin with, this transformation involved an internal reorganization of Yokohama City. In particular, a new Climate Change Policy Headquarter was established and a new managerial class of professionals from the business world emerged: "This effort could only be done by people invited from outside" (Yokohama City official).

As a result of these changes, a third of personnel were transferred in from outside or hired mid-career. These changes facilitated interactions between Yokohama City and businesses, and enhanced the city's attractiveness to companies. The fact that the current mayor and the head of the department in charge of smart city initiatives have previously worked in corporations operating in Yokohama City can be interpreted as continuity in these transformations.

An earlier step toward business-public partnership was the establishment in the 1984 of a hybrid public-private enterprise, the Yokohama Minato Mirai 21 Corporation, which was in charge of revitalizing the city center. The company counted the city government, Tokyo Gas and Tokyo Electric Power among its main shareholders, and soon became one of the protagonists in implementing the smart city policy.

The establishment of the YSCP Promotion Council in 2010 and the YSBA in 2015 followed this historical tendency to build a pathway that can be recognized and shared by both business and the state. Within this hybrid model, companies and the city government share objectives, as well as responsibility for the outcomes. Meetings are held every 
month for information sharing and consultation. These are important occasions for companies to exchange relevant information and obtain information from the city government about policy directions and government funding. Sometimes initiatives are taken by the city government, and at other times the companies contact Yokohama City to propose projects: "There are times when we make a proposal, and there are times when development companies ask us if there is any government funding" (Yokohama City official). Mutual exchange and partnerships aim to reinforce the relationship between these urban actors, thus enhancing the possibilities for long-term relationships.

Accordingly, Yokohama City has envisaged new ways to negotiate between public and private interests. It has established a consultation desk called the "Co-creation Front" where companies can present their proposals to Yokohama City. The latter then negotiates the proposal with the companies in relation to the project's objectives, the human, material and intellectual resources needed and the procedure to adopt to carry out the project. A set of Key Performance Indicators are then associated with each of these aspects in what has been called "Civic Co-creation Lean Canvas". This Canvas offers a scheme for negotiation. For instance, a corporate manager argues that policies and requests coming from Yokohama City are often "irrelevant and unprofitable" and the company needs to negotiate to transform them into something appealing for their business. On the other hand, the city needs to ensure that the project ultimately leads to a public benefit. The final objective is to reconcile these competing interests: "In the stage of implementing a specific project, it is necessary to overcome various 'adjustments'. The result is 'agreement"' (corporate participant). Open disagreements and disputes are not visible. As Obuchi (1987) commented, "a dispute is like a disease" in Japan (p. 81). Although reaching agreements on projects is the fruit of a historical process, the collaboration between these actors is also enabled by cultural proximity, the origins of which are discussed below.

\subsection{Samurai ethos}

The changes undertaken during the Meji Restoration also laid the foundations for the contemporary public administrative apparatus, as municipal governments were established for the first time (Sorensen, 2012). Members of this emerging bureaucratic apparatus were mainly the ex-samurai who had brought about the Restoration (Fulcher, 1988). In their transformation from warriors into bureaucrats, the samurai created a distinctive system of values from their education and training in Japanese Confucianism. In particular, political loyalty, obedience, respect for authority, and self-restraint were the main virtues promoted by Japanese Confucianism, which were carried over to the new bureaucratic elite.

The Confucian ethical ideal, combined with strong nationalism, also shaped the character of the Meiji entrepreneurial class. Following the dismantling of the samurai class, many ex-samurai became the new business class. Business and commerce were afforded lower status at that time, and the Confucian samurai ethos was mobilized to legitimize business affairs and prompt the modernization of the economy (Johnston and Selsky, 2005; Kaplan, 1972; Lockwood, 1965). "The samurai image of service for the public welfare was thus transferred to the modern entrepreneur" (Lockwood, 1965: 246), and 
bureaucrats and businessmen were educated to share a sense of national purpose (Hirschmeier, 1970). The emerging enterprises also carried on the traditional value system based on familism and groupism (Hirschmeier, 1970). The foundations of modern Japan were thus laid on a set of cultural and traditional values: desire for consensus, group membership, identification with harmony ( $w a)$, and a capacity to compromise by adjusting to others' opinions and avoiding conflict and direct confrontation (Hirschmeier, 1970).

This approach resonates with our findings on city-business relationships in Yokohama smart city. Like the government, Yokohama City seems to enjoy a power that is not merely economic but is rooted in the privileged status historically enjoyed by the samurai and carried over to the bureaucratic elite. Similarly, in service for public welfare, companies see a way to legitimize their identity in the eyes of their customers. Yokohama smart city is often referred to as a "brand" that the Yokohama City can give and companies can use to legitimize and promote their businesses. In a marketized world, cities are indeed called to capitalize on their image, and Yokohama is no exception. However, in the Japanese context, it is not only a market, but also refers to the public image (omote) of trustworthiness, which is associated with the public sector and has its roots in Japanese traditions. All of our interviewees referred to trustworthiness as a key attribute of the public sector. For instance, one explained that:

It is hard to believe what the private sector is saying because it is based on profit, but some people say that what the government is saying is trustworthy [...] they still believe what Yokohama City says (YSBA corporate participant).

The same sentiment was expressed by a city official:

The machines are purchased by citizens. The city of Yokohama explains to them that the project is primarily aimed at preventing global warming. If a business salesman comes, they may say, "go home", but if a Yokohama City official comes, they listen.

This allows Japanese local governments to preserve a public image that is particularly attractive to private corporations seeking to legitimize themselves and publicize their businesses to the general public and overseas. Furthermore, Yokohama City can use its "public image" to facilitate and coordinate relationships between companies:

Sellers have asked Yokohama City to approach buyers. We in Yokohama City are more trusted than sellers. Since the city of Yokohama acts as an intermediary, the buyer company listens to the seller. If the company suddenly goes to a building and asks for a BEMS [building energy management system], they won't listen. (Yokohama City official)

We see that the traditional profitability/market logics are often at odds with public projects, and that in such cases, businesses may decide to prioritize their relationships with the public actor over market interests: "There were times when we refused projects for economic reasons, but the top management of Yokohama City asked us to work at the 
head office. In that case, we have no choice but to reconsider" (YSBA corporate participant). As this quote shows, the collaboration between these actors cannot easily be defined in terms of a transactional relationship.

Market evaluations are often set aside, as the companies seek to maintain good relationships with public actors. For instance, a corporate manager suggested that "there is a negotiation to lose money here, but make a profit there. However, the public-related business is mostly a loss". The same participant argued that "probably the administration and private companies in the West are drier; in Japan, you have to communicate at least like your old neighbors. To put it another way, it is similar to parents-in-law. More often. I have to go to the YSCP Executive Committee more than once a month. I also have to show my face to [Yokohama City official] once or twice a year".

Values such as loyalty and respect for hierarchy and authority are therefore very important in the partnership between Yokohama City and private companies. Another participant with experience in both the public and private sectors explained that corporations make efforts to work with and adjust to Yokohama City:

The [corporate] mission is to get along well with Yokohama City, so it is a failure if a conflict emerges there. Private companies are tailored to the public. Private companies learn how to behave through long, repetitive experiences with the public (Yokohama City official).

In explaining the nature of their relationships, the companies and the city government used a term similar to the notion of "co-creation". However, this has another dimension. The objective of co-creation is to cultivate a long-term relationship aiming at reconciling tension and achieve harmony $(w a)$. Achieving harmony requires indirect communication, avoidance of conflict and sharing a common purpose: "we have different values, but we try to avoid conflict. It is necessary to endure each other" (Yokohama City official). A corporate manager described the relationship with Yokohama City as a "loan relationship":

It's on loan. [...] "This time you cried (loss), so next time, good (let me make a profit)" is common. This is the same for both the private sector and the government ... Externally, it is a partnership, but on the inside, it is a relationship that continues a loan and loan relationship.

The objective of the partnership is to build reciprocity through debt. Reciprocal debt allows the relationship to last in the long term.

\section{Concluding remarks}

Our analysis suggests that smart cities are an interesting area of study to explore PPPs but largely understudied (Bovaird, 2005; Liu et al., 2020; Meijer and Bolívar, 2016). Addressing this gap, we have demonstrated the role that culture and historical conditions play in enabling more collaborative-type PPPs, which are especially important for smart city development (Liu et al., 2020). 
We identified a distinctive model of PPPs in Japanese smart city projects rooted in the tradition of "Japan incorporated" (A. Nakamura, 1998), "sponsored capitalism" (Lockwood, 1965) and samurai ethos. In Japan, smart city PPPs consist of mutual adjustments and longterm relationships aiming to define and achieve common goods, such as the reduction of carbon dioxide emissions, economic growth, and industrial development. This collaborative model also finds expression in the emergence of urban public managers, i.e. managers who are able to establish compromises between public and private interests because they belong to both the market world of big corporations and the governmental civic world.

Following a global trend, neoliberal reforms have been enforced in Japan since the 1980s and PPPs have been a key component of these reforms in the smart city context. However, we argued, PPPs represent a cultural and historical heritage in Japan emanating from a Japanese version of neoliberalism (Bockman and Eyal, 2002). In contrast with other smart cities (Hollands, 2008, 2015), the Japanese smart city initiatives offer indeed a model of neoliberalism (Brenner and Theodore, 2002) that cannot be equated with the all-encompassing marketization of the urban space that appeared in the West.

Public-private partnerships in smart cities are not fragile but are based on the traditional samurai ethos, a cultural glue that has held government and businesses together over history. They are grounded in a moral principle of Japanese culture, i.e. harmony $(w a)$, supported by related actions and interpersonal practices that are deemed legitimate, such as the practice of guessing (sontaku) and conflict avoidance. Despite the power asymmetry, government-business relationships thus rarely result in conflictual or polarized disputes around the worthiness of a smart city project. On the contrary, mutual adjustments, informal interactions, and reciprocal guidance are key in reconciling potential disagreements. On the same note, business legitimacy privileges values of trust, moral debt, and public image, beyond a purely market logic of capital accumulation.

Notwithstanding its merits, we caution against the universal portability of this Japanese model, especially in countries that do not have a long tradition of collaborative relationships (Koppenjan and de Jong, 2018). In unveiling the role that cultural and local factors play in conceiving and operationalizing PPPs, our analysis serves as an invitation for further reflection and debate on the need for context-sensitive investigations of these practices.

\section{Declaration of conflicting interests}

The authors declared no potential conflicts of interest with respect to the research, authorship, and/or publication of this article.

\section{Funding}

This project has been financed by JSPS KAKENHI (Grant number JP18K01914) and University of Shizuoka.

\section{ORCID iDs}

Daniela Pianezzi (iD https://orcid.org/0000-0003-4880-8351

Uddin (iD https://orcid.org/0000-0002-9857-7478 


\section{References}

Angelidou M (2017) The role of smart city characteristics in the plans of fifteen cities. Journal of Urban Technology 24(4): 3-28.

Appio F, Limab M and Sotirios P (2019) Understanding smart cities: Innovation ecosystems, technological advancements, and societal challenges. Technological Forecasting \& Social Change 142: $1-14$.

Baron M (2012) Do we need smart cities for resilience? Journal of Economics and Management 10: 32-46.

Bestor V, Bestor TC and Yamagata A (2011) Routledge Handbook of Japanese Culture and Society. Abingdon: Routledge.

Bockman J and Eyal G (2002) Eastern Europe as a laboratory for economic knowledge: The transnational roots of neoliberalism. American Journal of Sociology 108(2): 310-352.

Bovaird T (2005) Public governance: Balancing stakeholder power in a network society. International Review of Administrative Sciences 71(2): 217-228.

Brenner N and Theodore N (2002) Cities and the geographies of "actually existing neoliberalism". Antipode 34(3): 349-379.

Broadbent J, Gill J and Laughlin R (2003) Evaluating the private finance initiative in the National Health Service in the UK. Accounting, Auditing \& Accountability Journal 16(3): 422-445.

Datta A (2015) New urban utopias of postcolonial India: "entrepreneurial urbanization" in Dholera smart city, Gujarat. Dialogues in Human Geography 51(1): 3-22.

Domberger S, Farago S and Fernandez P (1997) Public and private sector partnering: A re-appraisal. Public Administration 75(4): 777-787.

Fulcher J (1988) The bureaucratization of the state and the rise of Japan. British Journal of Sociology 34(4): 228-254.

Gioia DA, Corley KG and Hamilton AL (2012) Seeking qualitative rigor in inductive research: Notes on the Gioia methodology. Organizational Research Methods 16(1): 15-31.

Grossi G and Pianezzi D (2017) Smart cities: Utopia or neoliberal ideology? Cities 69: 79-85. https://doi.org/10.1016/j.cities.2017.07.012.

Hirschmeier J (1970) The Japanese spirit of enterprise, 1867-1970. Business History Review 44(1): 13-38.

Hollands RG (2008) Will the real smart city please stand up? Intelligent, progressive or entrepreneurial? City 12(3): 303-320.

Hollands RG (2015) Critical interventions into the corporate smart city. Cambridge Journal of Regions Economy and Society 8(1): 61-77.

Hood C (1991) A public management for all seasons? Public Administration 69(1): 3-19.

Johnston S and Selsky J (2005) Duality and paradox: Trust and duplicity in Japanese business practice. Organization Studies 27(2): 183-205.

Jones RS and Kim M (2013) Restructuring the Electricity Sector and Promoting Green Growth in Japan. OECD Economics Department Working Papers No. 1069. https://dx.doi.org/10.1787/ $5 \mathrm{k} 43 \mathrm{nxrhfjtd}-\mathrm{en}$.

Kaplan EJ (1972) Japan: The Government-Business Relationship: A Guide for the American Businessman. Washington, DC: US Bureau of International Commerce.

Kikkawa T (2021) Saigo Nihon no Denryokugyou: Rekisiteki Tenkanten wo Koete (Japanese). Nagoya: Nagoya University Press.

Koppenjan J and de Jong M (2018) The introduction of public-private partnerships in the Netherlands as a case of institutional bricolage: The evolution of an Anglo-Saxon transplant in a Rhineland context. Public Administration 96(1): 171-184. 
Koppenjan JFM, Koppenjan J and Klijn EH (2004) Managing Uncertainties in Networks: A Network Approach to Problem Solving and Decision Making. London: Routledge.

Liu T, Mostafa S, Mohamed S, et al. (2020) Emerging themes of public-private partnership application in developing smart city projects: A conceptual framework. Built Environment Project and Asset Management 11(1): 138-156.

Lockwood WW (1965) State and Economic Enterprise in Japan. Princeton, NJ: University Press.

Lombardi P and Vanolo A (2015) Smart city as a mobile technology: Critical perspectives on urban development policies. In: Rodríguez-Bolívar MP (eds) Transforming City Governments for Successful Smart Cities. Cham: Springer, 147-161.

Mah DNY, Wu YY, Ip JCM, et al. (2013) The role of the state in sustainable energy transitions: A case study of large smart grid demonstration projects in Japan. Energy Policy 63: 726-737. https://doi.org/10.1016/j.enpol.2013.07.106.

Meijer A and Bolívar M (2016) Governing the smart city: A review of the literature on smart urban governance. International Review of Administrative Sciences 82(2): 392-408.

Nag R and Gioia DA (2012) From common to uncommon knowledge: Foundations of firm-specific use of knowledge as a resource. Academy of Management Journal 55(2): 421-457.

Nakamura A (1998) Tokyo Government tries governance: Development and problems of public administration in Japan's capital city. International Review of Administrative Sciences 64(2): 235-246.

Nakamura H (1978) Japan, incorporated and postwar democracy. Japanese Economic Studies 6(34): $68-109$.

Nesti G (2020) Defining and assessing the transformational nature of smart city governance: Insights from four European cases. International Review of Administrative Sciences 86(1): 20-37.

Obuchi T (1987) Role of the court in the process of informal dispute resolution in Japan: Traditional and modern aspects, With special emphasis on in-court compromise. Law Japan 20: 74-101.

Pham C (2014) Smart Cities in Japan. An Assessment on the Potential for Eu-Japan Cooperation and Business Development. Tokyo: EU-Japan Centre for Industrial Cooperation.

Reeves E (2008) The practice of contracting in public private partnerships: Transaction costs and relational contracting in the Irish schools sector. Public Administration 86(4): 969-986.

Reissner SC (2019) "We are this hybrid": Members' search for organizational identity in an institutionalized public-private partnership. Public Administration 97(1): 48-63.

Rodríguez-Bolívar MP (2015) Transforming City Governments for Successful Smart Cities. Cham: Springer.

Ruhlandt RWS (2018) The governance of smart cities: A systematic literature review. Cities 81: 123. https://doi.org/10.1016/j.cities.2018.02.014.

Schwartz FJ (2001) Advice and Consent: The Politics of Consultation in Japan. Cambridge: Cambridge University Press.

Shapiro JM (2006) Smart cities: Quality of life, productivity, and the growth effects of human capital. Review of Economics and Statistics 88(2): 324-335.

Söderström O, Paasche T and Klauser F (2014) Smart cities as corporate storytelling. City 18(3): 307-320.

Sorensen A (2012) The state and social capital in Japan. In: Daniere A and Van Luong H (eds) The Dynamics of Social Capital and Civic Engagement in Asia. Abingdon: Routledge, 163-181.

Steijn B, Klijn EH and Edelenbos J (2011) Public private partnerships: Added value by organizational form or management? Public Administration 89(4): 1235-1252.

Turner SF and Rindova V (2012) A balancing act: How organizations pursue consistency in routine functioning in the face of ongoing change. Organization Science 23(1): 24-46. 
Vanolo A (2014) Smartmentality: The smart city as disciplinary strategy. Urban Studies 51(5): 883-898.

Veselitskaya N, Karasev O and Beloshitskiy A (2019) Drivers and barriers for smart cities development. Theoretical and Empirical Researches in Urban Management 14(1): 85-110.

Wang H, Xiong W, Wu G, et al. (2018) Public-private partnership in public administration discipline: A literature review. Public management review 20(2): 293-316. 